\title{
Degree of freezing does not affect efficacy of frozen gloves for prevention of docetaxel-induced nail toxicity in breast cancer patients
}

\author{
H. Ishiguro • S. Takashima $\cdot$ K. Yoshimura $~ I$ I. Yano • T. Yamamoto $\cdot$ M. Niimi • \\ H. Yamashiro • T. Ueno • M. Takeuchi • T. Sugie • K. Yanagihara • M. Toi • \\ M. Fukushima
}

Received: 13 June 2011 / Accepted: 25 October 2011 /Published online: 16 November 2011

(C) The Author(s) 2011. This article is published with open access at Springerlink.com

\begin{abstract}
Purpose Frozen gloves (FG) are effective in preventing docetaxel-induced nail toxicity (DNT), but uncomfortable. The preventive effect of FG for DNT was compared using a standard $\left(-25\right.$ to $\left.-30^{\circ} \mathrm{C}\right)$ or more comfortable $\left(-10\right.$ to $\left.-20^{\circ} \mathrm{C}\right)$ preparation.

Methods Breast cancer patients receiving docetaxel were eligible. Each patient wore an FG (prepared at -10 to $-20^{\circ} \mathrm{C}$ for $90 \mathrm{~min}$ ) for $60 \mathrm{~min}$ without replacement on the right hand. The left hand was protected by standard methods
\end{abstract}

Part of this study was presented as an oral abstract in the "Fatigue, Mucositis, Cutaneous Toxicity" session (abstract number A-327-000300192) at the 2011 Multinational Association of Supportive Care in Cancer/International Society of Oral Oncology.

H. Ishiguro $(\bowtie) \cdot S$. Takashima $\cdot \mathrm{K}$. Yanagihara

Outpatient Oncology Unit, Kyoto University Hospital,

Kyoto, Japan

e-mail: hishimd@kuhp.kyoto-u.ac.jp

K. Yoshimura $\cdot$ T. Yamamoto $\cdot$ M. Niimi

Translational Research Center, Kyoto University Hospital,

Kyoto, Japan

\section{Yano}

Graduate School of Pharmaceutical Sciences, Kyoto University,

Kyoto, Japan

H. Yamashiro

Breast Surgery Department, Mitsubishi Kyoto Hospital,

Kyoto, Japan

T. Ueno $\cdot$ M. Takeuchi $\cdot$ T. Sugie $\cdot$ M. Toi

Breast Surgery Department, Kyoto University Hospital,

Kyoto, Japan

M. Fukushima

Translational Research Informatics Center,

Kobe, Japan
(FG prepared at -25 to $-30^{\circ} \mathrm{C}$ overnight and worn for $90 \mathrm{~min}$ with replacement at $45 \mathrm{~min}$ ). The primary endpoint was DNT occurrence at 5 months. Secondary endpoints included docetaxel exposure [cumulative dose and area under the blood concentration time curve (AUC)] until DNT occurrence and discomfort from FG. The pharmacokinetics of docetaxel was assessed. Results From 23 patients enrolled between December 2006 and June 2010, seven who received docetaxel for less than 5 months were excluded from evaluation. The median accumulated docetaxel dose was $700 \mathrm{mg} / \mathrm{m}^{2}$ (340$1430 \mathrm{mg} / \mathrm{m}^{2}$ ). Within 5 months of FG use, none developed protocol-defined DNT in either hand. Two patients (13\%) developed DNT at 7.2 and 7.3 months, respectively, both at -10 to $-20^{\circ} \mathrm{C}$. In the control hand $\left(-25\right.$ to $\left.-30^{\circ} \mathrm{C}\right)$, discomfort occurred in $92 \%$ of the cycles, compared to $15 \%$ in the experimental hand $\left(-10\right.$ to $\left.-20^{\circ} \mathrm{C}\right)$. Five patients $(22 \%)$ experienced pain at -25 to $-30^{\circ} \mathrm{C}$, but none did at -10 to $-20^{\circ} \mathrm{C}$. The degree of docetaxel exposure was not related to DNT occurrence in our study. Conclusion A convenient preparation of $\mathrm{FG}$ at -10 to $-20^{\circ} \mathrm{C}$ is almost as effective as a standard preparation at -25 to $-30^{\circ} \mathrm{C}$, with significantly less discomfort.

Keywords Chemotherapy $\cdot$ Docetaxel $\cdot$ Frozen glove $\cdot$ Nail toxicity Pharmacokinetics

\section{Introduction}

Taxanes such as docetaxel and paclitaxel have been widely used for the treatment of various types of cancers, including breast, lung, gynecological and gastric cancers, as palliative chemotherapies. Since common adverse effects such as 
bone marrow and gastrointestinal toxicities have become manageable due to the development of granulocyte colonystimulating factor (G-CSF) $[1,2]$ and $5-\mathrm{HT}_{3}$ antagonists [3, 4], the adverse events related to cutaneous toxicities after taxane treatment have become more important. The important cutaneous toxicities due to taxane treatment include hand-foot skin syndrome and nail-related adverse events. Minisini et al. have reported that more than $40 \%$ of patients treated with taxanes developed nail toxicities [5]. In our department, approximately $45 \%$ of patients receiving docetaxel treatment for 4 months or longer developed clinically significant nail toxicities (unpublished data). This is especially relevant for breast cancer patients, who received higher doses of taxanes than patients with other types of cancer: more than $60 \%$ of these patients showed clinically significant nail toxicities. Nail toxicities include pigmentation, onychitis, onycholysis, hemorrhage and tenderness in the nail bed. Although these adverse events are not life threatening, they do not recover in a short period of time and make it difficult to continue chemotherapy, resulting in negative consequences for the patient's prognosis.

Scottë et al. reported that applying Elasto-Gel frozen gloves (FG) reduced nail-related adverse events in patients receiving docetaxel at $75 \mathrm{mg} / \mathrm{m}^{2}$ alone or in combination chemotherapy [6]. They used gloves frozen at -25 to $-30^{\circ} \mathrm{C}$, and $11 \%$ of patients dropped out of the study after experiencing discomfort due to cold intolerance. In our pilot trial, frozen gloves were also applied; however, some patients were not able to wear them for a predetermined period (90 $\mathrm{min}$ ) due to discomfort (cold intolerance). Several studies have demonstrated the usefulness of the vasoconstrictor effect of cold stimulation on oral cavities (oral cryotherapy) and the scalp (scalp cooling system) [7-10]. For example Ridderheim et al. reported that maintaining a constant scalp temperature of $+5^{\circ} \mathrm{C}$ prevented alopecia in patients treated with anthracyclines [9]. In oral cryotherapy, it is very unlikely that oral cavity temperatures are maintained at $0^{\circ} \mathrm{C}$ or less [10]. In addition, it may be impossible to use a $-30^{\circ} \mathrm{C}$ freezer in some medical facilities; therefore, the temperature of $-10^{\circ}$ to $-20^{\circ} \mathrm{C}$ which can be maintained by the freezer compartment of a household refrigerator may be ideal for routine clinical use. From our careful clinical observations of eight hospital staff volunteers, there were no differences in the duration of the cooling effect or in skin temperatures of the hands and fingers between gloves frozen at -25 to $-30^{\circ} \mathrm{C}$ and -10 to $-20^{\circ} \mathrm{C}$. Some had redness and increased skin temperatures possibly due to reactive increase in blood flow in the hand wearing the glove frozen at -25 to $-30^{\circ} \mathrm{C}$. Furthermore, seven out of eight volunteers experienced discomfort due to cold intolerance only in the hand wearing the glove frozen at -25 to $-30^{\circ} \mathrm{C}$ [11].
Based on these results, we designed a study to compare the cooling effects in each individual patient between one control hand wearing a glove frozen for at least overnight at -25 to $-30^{\circ} \mathrm{C}$, for $90 \mathrm{~min}$, and the other experimental hand wearing a glove frozen at -10 to $-20^{\circ} \mathrm{C}$. Considering the maximum blood concentration time $\left(T_{\max }\right)$ of docetaxel $(60 \mathrm{~min}$ after the initiation of dosing) [12], the patients wore a single glove on the experimental side (the glove frozen at -10 to $-20^{\circ} \mathrm{C}$ for $90 \mathrm{~min}$ ) from $15 \mathrm{~min}$ after the initiation of docetaxel infusion to $15 \mathrm{~min}$ after the end of the infusion, in order to enable a single glove to cover the hand during the $60 \mathrm{~min}$ around the time point of maximum drug concentration.

In general, each patient currently requires four gloves in total daily (two for each hand), frozen for at least $3 \mathrm{~h}$ or overnight; however, if an alternative method is available using only two gloves in total daily (one for each hand) that are frozen for a shorter duration (90 $\mathrm{min}$, the time required for the patient's blood test results to become available), it may be more practical for clinical use.

\section{Patients and methods}

\section{Study population}

Women eligible for this study were pathologically proven stage IV or recurrent breast cancer patients who were not candidates for curative surgery, between 20 and 69 years of age, Eastern Cooperative Oncology Group (ECOG) performance status 0 to 2 with adequate organ functions, scheduled to receive docetaxel at $40 \mathrm{mg} / \mathrm{m}^{2}$ or more at least once a month and who had not received more than two doses of docetaxel on entry to the study. The criteria for exclusion included peripheral neuropathy, edema, Raynaud's symptoms or peripheral arterial ischemia which were graded 2 or higher, the presence of suspected metastasis in the bone, soft tissue or skin of the hands, the presence of pleural and pericardial effusion and ascites requiring drainage, and pre-existing nail toxicities which were scored as equal to or higher than 5 by protocoldefined scoring. All participants gave their written informed consent prior to their inclusion in this study.

\section{Study design}

In this self-controlled trial, we compared the efficacy and discomfort of FG (Elasto-Gel flexible gloves, 84400 APT Cedex, Akromed, France) prepared using different degrees of freezing. Patients enrolled onto this study were to receive docetaxel over $1 \mathrm{~h}$ after appropriate premedication such as dexamethasone. Some patients also received other chemotherapeutic agents in combination and/or zoledronic acid. 
For each patient, three frozen gloves were prepared and used as follows. As standard protection (control), each patient wore an FG on the left hand which was prepared at -25 to $-30^{\circ} \mathrm{C}$ at least overnight. These $\mathrm{FG}$ were worn on the left hand from 15 min before docetaxel administration, during the 1-h docetaxel infusion and until $15 \mathrm{~min}$ after the end of infusion, a total duration of $90 \mathrm{~min}$. In order to maintain the low temperature, two gloves were used successively for 45 min each [6]. On the right hand, each patient wore an FG prepared at -10 to $-20^{\circ} \mathrm{C}$ for $90 \mathrm{~min}$ in the freezer compartment of a household refrigerator. This was used from $15 \mathrm{~min}$ after the start of docetaxel infusion until $15 \mathrm{~min}$ after the end of docetaxel infusion, a total of $60 \mathrm{~min}$.

This study was approved by the Ethics Committee of Kyoto University Graduate School of Medicine (C-79) and conducted in accordance with the Ethical Guidelines for Clinical Studies by the Ministry of Health, Labour and Welfare, Japan (July 30, 2003, amended December 28,
2004) and the Helsinki Declaration (1964, amended in 1975, 1983, 1989, 1996, 2000 and 2004) of the World Medical Association. This study was registered to the University Hospital Medical Information Network Clinical Trials Registry (UMIN-CTR) managed by the National University Hospital Council of Japan and operated by the University of Tokyo Hospital (UMIN000000478).

\section{Assessment}

Nail toxicities and discomfort due to FG were assessed and graded by the National Cancer Institute Common Toxicity Criteria for Adverse Events (CTCAE) v3.0 before study entry and prior to every docetaxel administration in the Outpatient Oncology Unit. Nail toxicity was documented by photography and scored as follows. Grade 1 nail toxicity was given 1 point for each finger with a maximum of 5 points per hand.

Table 1 Baseline clinical characteristics of all enrolled patients and those evaluable for frozen glove efficacy

\begin{tabular}{|c|c|c|c|c|c|c|}
\hline & & & Enrolled & & Evaluable & \\
\hline & & & $n$ & $\%$ & $n$ & $\%$ \\
\hline & & & 23 & & 16 & \\
\hline \multirow[t]{5}{*}{ Age (years) } & & Median & 58 & & 59 & \\
\hline & & Range & $40-68$ & & $44-68$ & \\
\hline & & $<50$ & 4 & 17 & 2 & 13 \\
\hline & & $\geq 50,<60$ & 11 & 48 & 8 & 50 \\
\hline & & $\geq 60$ & 8 & 35 & 6 & 38 \\
\hline \multirow[t]{4}{*}{ Complications } & & Peripheral neuropathy & 1 & 4 & 1 & 6 \\
\hline & & Edematous hand & 1 & 4 & 1 & 6 \\
\hline & & Raynaud's symptoms & 0 & 0 & 0 & 0 \\
\hline & & Peripheral arterial ischemia & 0 & 0 & 0 & 0 \\
\hline \multirow[t]{3}{*}{ Smoking history } & & Never & 20 & 87 & 13 & 81 \\
\hline & & Yes & 2 & 9 & 2 & 13 \\
\hline & & Unknown & 1 & 4 & 1 & 6 \\
\hline Performance status & & 0 & 23 & 100 & 16 & 100 \\
\hline \multirow[t]{13}{*}{ Prior chemotherapy } & & None & 5 & 22 & 3 & 19 \\
\hline & & Yes & 18 & 78 & 13 & 81 \\
\hline & 5-Fluoropyrimidine & UFT & 2 & 9 & 2 & 13 \\
\hline & & Doxifluridine & 9 & 39 & 8 & 50 \\
\hline & & Capecitabine & 8 & 35 & 5 & 31 \\
\hline & & S-1 & 6 & 26 & 4 & 25 \\
\hline & & Fluorouracil & 2 & 9 & 2 & 13 \\
\hline & Anthracycline & Doxorubicin & 1 & 4 & 0 & 0 \\
\hline & & Epirubicin & 4 & 17 & 3 & 19 \\
\hline & Taxane & Paclitaxel & 3 & 13 & 3 & 19 \\
\hline & Vinca alkaloid & Vinorelbine & 1 & 4 & 1 & 6 \\
\hline & Alkylating & Cyclophosphamide & 16 & 70 & 11 & 69 \\
\hline & Others & MTX, MMC, CBDCA & 1 & 4 & 1 & 6 \\
\hline
\end{tabular}

$M T X$ methotrexate, $M M C$ mitomycin C, $C B D C A$ carboplatin 
Table 2 Treatment and pharmacokinetic results of all enrolled patients and those evaluable for frozen glove efficacy

\begin{tabular}{|c|c|c|c|c|c|c|}
\hline & & & \multicolumn{2}{|l|}{ Enrolled } & \multicolumn{2}{|l|}{ Evaluable } \\
\hline & & & $\begin{array}{l}n \\
23\end{array}$ & $\%$ & $\begin{array}{l}n \\
16\end{array}$ & $\%$ \\
\hline \multirow{2}{*}{\multicolumn{2}{|c|}{ Total docetaxel dose $\left(\mathrm{mg} / \mathrm{m}^{2}\right)$}} & Median & 560 & & 700 & \\
\hline & & Range & $80-1430$ & & $340-1430$ & \\
\hline \multirow[t]{4}{*}{ Duration of docetaxel (months) } & & Median & 9.0 & & 11.5 & \\
\hline & & Range & $0.6-24.3$ & & $5.3-24.3$ & \\
\hline & & $<5.0$ & 7 & 30 & 0 & 0 \\
\hline & & $\geq 5.0$ & 16 & 70 & 16 & 100 \\
\hline \multirow[t]{11}{*}{ Combination chemotherapy } & & No & 3 & 13 & 1 & 6 \\
\hline & & Yes & 20 & 87 & 15 & 94 \\
\hline & Cytotoxic agent & Cyclophosphamide & 8 & 35 & 6 & 38 \\
\hline & & Capecitabine & 1 & 4 & 0 & 0 \\
\hline & & Epirubicin & 2 & 9 & 2 & 13 \\
\hline & Hormonal agent & Anastrozole & 1 & 4 & 0 & 0 \\
\hline & & Letrozole & 7 & 30 & 5 & 31 \\
\hline & & Exemestane & 3 & 13 & 3 & 19 \\
\hline & & MPA & 1 & 4 & 0 & 0 \\
\hline & & LH-RH analogue & 1 & 4 & 0 & 0 \\
\hline & Molecular target & Trastuzumab & 5 & 22 & 4 & 25 \\
\hline \multirow[t]{10}{*}{ Pharmacokinetics $^{\mathrm{a}}$} & AUC (mg*h/L) & Median & 1.73 & & 1.76 & \\
\hline & & Range & $1.14-2.78$ & & $1.14-2.78$ & \\
\hline & Clearance $(\mathrm{L} / \mathrm{h})$ & Median & 34.7 & & 34.6 & \\
\hline & & Range & $22.8-52.2$ & & $23.0-51.9$ & \\
\hline & Clearance/BSA $\left(\mathrm{L} / \mathrm{h} / \mathrm{m}^{2}\right)$ & Median & 22.9 & & 22.6 & \\
\hline & & Range & $14.5-35.6$ & & $14.5-35.6$ & \\
\hline & $C_{\max }(\mathrm{mg} / \mathrm{mL})$ & Median & 1.57 & & 1.57 & \\
\hline & & Range & $0.94-2.34$ & & $0.94-2.34$ & \\
\hline & $V_{\mathrm{ss}}(\mathrm{L})$ & Median & 12.5 & & 12.6 & \\
\hline & & Range & $6.10-36.7$ & & $8.07-36.7$ & \\
\hline
\end{tabular}

${ }^{a}$ One patient whose pharmacokinetic analysis was not carried out correctly was excluded from enrolled and evaluable cohorts $A U C$ area under the blood concentration time curve, BSA body surface area, $C_{\max }$ maximum concentration, $V_{S S}$ volume in steady state, $M P A$ medroxyprogesterone acetate, $L H-R H$ luteinizing hormone releasing hormone

Grade 2 nail toxicity was given 5 points for each finger. Total points for each hand were recorded for docetaxelinduced nail toxicity (DNT).

\section{Pharmacokinetics}

The pharmacokinetics of docetaxel was assessed within 1 month of enrollment. Blood samples were obtained prior to docetaxel infusion, immediately before the end of infusion and 10,30,60,120 and 180 min after the end of infusion. Drug concentration was measured by high performance liquid chromatography with tandem mass spectrometry. Pharmacokinetic parameters were calculated with the software WinNonlin (Pharsight Co., Mountain View, CA) using the two-compartment model.
Table 3 Primary endpoint: protocol-defined docetaxelinduced nail toxicity (DNT) occurrence by 5 months

\begin{tabular}{llllll}
\hline & & Number & Event & Rate (\%) & 95\% Confidence interval \\
\hline Left hand & Standard: -25 to $-30^{\circ} \mathrm{C}$ & 16 & 0 & 0 & $0-21 \%$ \\
Right hand & Experimental: -10 to $-20^{\circ} \mathrm{C}$ & 16 & 0 & 0 & $0-21 \%$ \\
\hline
\end{tabular}


Table 4 Secondary endpoint: docetaxel exposure and duration before occurrence of protocol-defined DNT

\begin{tabular}{lllllll}
\hline Case ID & Hand & $\begin{array}{l}\text { Duration until DNT } \\
\text { occurrence (days) }\end{array}$ & $\begin{array}{l}\text { Docetaxel dose until DNT } \\
\text { occurrence }\left(\mathrm{mg} / \mathrm{m}^{2}\right)\end{array}$ & $\begin{array}{l}\text { Total docetaxel } \\
\text { dose }\left(\mathrm{mg} / \mathrm{m}^{2}\right)\end{array}$ & $\begin{array}{l}\text { Total } \\
\text { duration(days) }\end{array}$ & Type of event \\
\hline 4 & Right & 222 & 440 & 640 & 307 & Pigmentation, hemorrhage, pain \\
10 & Right & 220 & 480 & 1360 & 585 & Tenderness \\
\hline
\end{tabular}

\section{Statistical methodology}

The primary endpoint was DNT occurrence (more than a 2point increase in nail toxicity scoring or any grade 2 toxicity) by 5 months. Secondary endpoints were as follows: any grade 2 or higher DNT occurrence by 5 months, docetaxel exposure [cumulative dose and area under the blood concentration time curve (AUC)] and time until DNT occurrence, discomfort from FG and a detailed description of specific DNT type.

It was estimated that the protective effect of FG on the control hand would be $90 \%$ (DNT 10\%) at 5 months. The expected protection rate for the experimental side was $85 \%$, and at least higher than $50 \%$ which is the protection rate without FG in the literature [6]. It was estimated that analysis of 20 patients was required for a statistical power of $80 \%$. To be eligible for FG efficacy evaluation, patients must have received more than five doses of docetaxel with a total of at least $160 \mathrm{mg} / \mathrm{m}^{2}$ or more, over 5 months or longer. A total enrollment of 25 patients was required for $80 \%$ of the enrolled patients to be evaluable for FG efficacy.

\section{Results}

Patients

The patients' demographic information is listed in Table 1 . The performance status (PS) of all enrolled patients $(n=23)$ was 0 . About $80 \%$ of patients had received chemotherapy before enrollment, and most of these patients had received 5fluoropyrimidines, such as UFT, S-1 and capecitabine. The next most common chemotherapy was cyclophosphamide in $70 \%$ of patients. Treatment information is summarized in
Table 2. The total cumulative dose of docetaxel and duration of administration was $560 \mathrm{mg} / \mathrm{m}^{2}\left(80-1430 \mathrm{mg} / \mathrm{m}^{2}\right)$ and 9.0 months (0.6-24.3 months). Common concurrent cytotoxic and hormonal agents were cyclophosphamide and letrozole, respectively.

\section{Efficacy of FG}

Sixteen patients met the pre-specified criteria for $\mathrm{FG}$ efficacy evaluation. The total cumulative dose of docetaxel and duration of administration was $700(340-1430) \mathrm{mg} / \mathrm{m}^{2}$ and 11.5 (5.3-24.3)months within the population evaluated for FG efficacy (Table 2). None of the 16 evaluable patients developed protocol-defined DNT before 5 months in either hand (Table 3).

After the initial evaluation period for the primary endpoint, two patients developed protocol-defined DNT at 7.2 and 7.3 months, respectively (Table 4). The first patient (case \#4) developed grade 2 DNT (pain with nail pigmentation, and hemorrhage in the nail bed), and the cumulative docetaxel dose was $440 \mathrm{mg} / \mathrm{m}^{2}$ before development of DNT. Administration of docetaxel was terminated in this patient due to recurrence of DNT and progressive disease within a few months. The second patient (case \#10) developed nail tenderness with no other changes in the nails at a docetaxel dose of $480 \mathrm{mg} / \mathrm{m}^{2}$; however, this may not be related to docetaxel since this patient was able to receive further docetaxel doses of $880 \mathrm{mg} / \mathrm{m}^{2}$ (total $1360 \mathrm{mg} / \mathrm{m}^{2}$ ) without recurrence of DNT.

Adverse events due to FG

Although none of the enrolled patients discontinued FG use due to intolerance, $100 \%$ (95\% confidential interval 85
Table 5 Adverse events due to use of frozen gloves (FG) in all enrolled patients: any discomfort due to FG at 5 months-by patient and by cycle

\begin{tabular}{|c|c|c|c|c|}
\hline By patient & $N$ & Events & Rate $(\%)$ & $95 \% \mathrm{CI}$ \\
\hline Left hand Standard: -25 to $-30^{\circ} \mathrm{C}$ & 23 & 23 & 100 & $85-100 \%$ \\
\hline Right hand Experimental: -10 to $-20^{\circ} \mathrm{C}$ & 23 & 12 & 52 & $30-73 \%$ \\
\hline By cycle & Cycles & Events & Rate $(\%)$ & $95 \% \mathrm{CI}$ \\
\hline Left hand Standard: -25 to $-30^{\circ} \mathrm{C}$ & 146 & 135 & 92 & $87-96 \%$ \\
\hline Right hand Experimental: -10 to $-15^{\circ} \mathrm{C}$ & 146 & 22 & 15 & $10-22 \%$ \\
\hline
\end{tabular}


Table 6 Other adverse events due to FG

Worst grade

\begin{tabular}{|c|c|c|c|c|c|c|c|}
\hline$n=23$ & & 0 & 1 & 2 & 3 & 4 & $\geq$ Grade $1(\%)$ \\
\hline \multirow[t]{2}{*}{ Allergic reaction } & Left hand (standard: -25 to $-30^{\circ} \mathrm{C}$ ) & 23 & 0 & 0 & 0 & 0 & 0 \\
\hline & Right hand (experimental: -10 to $-15^{\circ} \mathrm{C}$ ) & 23 & 0 & 0 & 0 & 0 & 0 \\
\hline \multirow[t]{2}{*}{ Pain } & Left hand (standard: -25 to $-30^{\circ} \mathrm{C}$ ) & 18 & 5 & 0 & 0 & 0 & 22 \\
\hline & Right hand (experimental: -10 to $-15^{\circ} \mathrm{C}$ ) & 23 & 0 & 0 & 0 & 0 & 0 \\
\hline \multirow[t]{2}{*}{ Sensory neuropathy } & Left hand (standard: -25 to $-30^{\circ} \mathrm{C}$ ) & 22 & 1 & 0 & 0 & 0 & 4 \\
\hline & Right hand (experimental: -10 to $-15^{\circ} \mathrm{C}$ ) & 22 & 1 & 0 & 0 & 0 & 4 \\
\hline \multirow[t]{2}{*}{ Arthritis } & Left hand (standard: -25 to $-30^{\circ} \mathrm{C}$ ) & 23 & 0 & 0 & 0 & 0 & 0 \\
\hline & Right hand (experimental: -10 to $-15^{\circ} \mathrm{C}$ ) & 22 & 0 & 1 & 0 & 0 & 4 \\
\hline
\end{tabular}

$100 \%$ ) and 52\% (95\% confidential interval 30-73\%) of patients complained of discomfort at least once in their left $\left(-25\right.$ to $\left.-30^{\circ} \mathrm{C}\right)$ and right $\left(-10\right.$ to $\left.-20^{\circ} \mathrm{C}\right)$ hands, respectively, by 5 months of FG use $(p<0.001$ by McNemer test; Table 5). When these results were analyzed by treatment cycle, the values were $92 \%$ (95\% confidential interval $87-$ $96 \%$ ) and $15 \%$ (95\% confidential interval $10-22 \%)$, respectively $(p<0.001$ by permutation test; Table 5). Specific adverse events observed were pain (five patients= $22 \%$, all events in the left hand), sensory neuropathy (one event in the right hand, one event in the left, each in a different patient) and arthritis (one patient in the right hand) (Table 6).

\section{Pharmacokinetic correlation}

The AUC $(n=22)$ of docetaxel (at $40 \mathrm{mg} / \mathrm{m}^{2}$ ) was 1.73 (1.14-2.78) $\mathrm{mg}^{*} \mathrm{~h} / \mathrm{L}$ for all enrolled patients except one whose pharmacokinetic analysis was not carried out correctly (Table 2). For patients evaluable for FG efficacy,

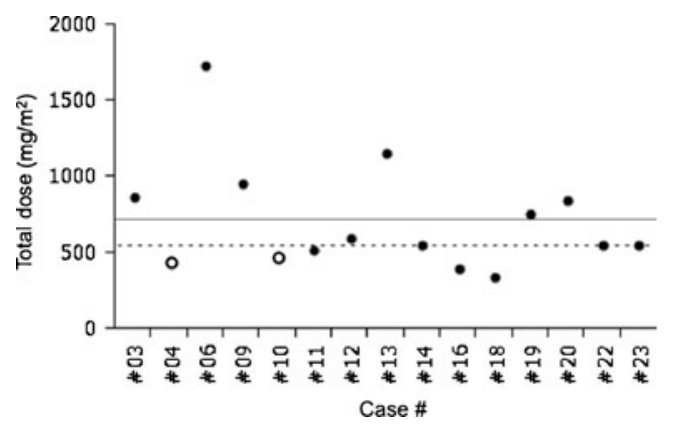

Fig. 1 Total docetaxel dose before development of docetaxel-induced nail toxicity (DNT) or study closure was plotted for patients who met the evaluation criteria for frozen glove efficacy and pharmacokinetics. Straight lines and broken lines indicate mean and median values, respectively. Open circles represent data from patients who developed DNT and closed circles from patients without DNT. This figure was created using the Microsoft Office Powerpoint and JMP program the total cumulative dose of docetaxel $(n=16)$ was 700 $(340-1430) \mathrm{mg} / \mathrm{m}^{2}$, and the AUC $(n=15)$ was $1.76(1.14$ 2.78) $\mathrm{mg}^{*} \mathrm{~h} / \mathrm{L}$ (Table 2). Clearance (CL, $\left.n=15\right)$ and $\mathrm{CL}$ adjusted by body surface area $(n=15)$ was $34.6(23.0-51.9)$ $\mathrm{L} / \mathrm{h}$ and $22.6(14.5-35.6) \mathrm{L} / \mathrm{h} / \mathrm{m}^{2}$ for those evaluable patients (Table 2), which seems to be slightly lower than figures reported for the Western population [13].

The AUC of case \#4, who developed DNT at day 222, was $1.71 \mathrm{mg}^{*} \mathrm{~h} / \mathrm{L}$, which was comparable to the median $\left(1.76 \mathrm{mg}^{*} \mathrm{~h} / \mathrm{L}\right)$ and mean $\left(1.78 \mathrm{mg}^{*} \mathrm{~h} / \mathrm{L}\right)$ AUC. She had received only $440 \mathrm{mg} / \mathrm{m}^{2}$ of docetaxel before DNT occurrence. The AUC of case \#10 was $1.14 \mathrm{mg} * \mathrm{~h} / \mathrm{L}$. She had received $480 \mathrm{mg} / \mathrm{m}^{2}$ of docetaxel before DNT. On the other hand, none of the four patients whose AUC and total dose were both higher than the median $\left(1.76 \mathrm{mg}^{*} \mathrm{~h} / \mathrm{L}\right.$ and $560 \mathrm{mg} / \mathrm{m}^{2}$, respectively), out of the 15 patients evaluable for both FG efficacy and pharmacokinetics, developed protocol-defined DNT (Figs. 1 and 2).

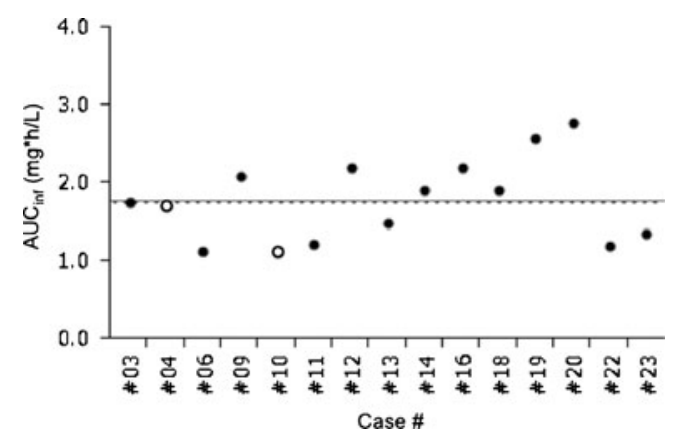

Fig. 2 Area under the blood concentration time curve (AUC) for docetaxel administered at $40 \mathrm{mg} / \mathrm{m}^{2}$ was plotted for patients who met the evaluation criteria for frozen glove efficacy and pharmacokinetics. Straight lines and broken lines indicate mean and median values, respectively. Open circles represent data from patients who developed DNT and closed circles from patients without DNT. This figure was created using the Microsoft Office Powerpoint and JMP program. $A U C_{\text {inf }}$ area under the blood concentration time curve extrapolated to infinity 


\section{Discussion}

This study compared the effectiveness of FG prepared in two different ways and used on the right and left hand in the same patient. The standard application of FG was quite effective for DNT prevention but caused significant discomfort similar to that reported in the literature [6]. On the other hand, the more convenient method including preparation for a shorter time at higher temperature as well as a shorter duration of application without FG replacement was not only as effective as the standard method but also caused less discomfort and was economically beneficial. The occurrence of DNT seems not to be predictable from simple docetaxel exposure.

This self-controlled study was neither blinded nor randomized, but comparison of the right and left hand in the same patient gives less bias relative to historical control comparisons. It is also unknown whether our findings can be applied to other taxane agents such as paclitaxel, including albumin-bound paclitaxel.

Another possible weakness of this study was the relatively lower starting dose of docetaxel $\left(40 \mathrm{mg} / \mathrm{m}^{2}\right)$ because the study protocol allowed for combination chemotherapy. In fact, $50 \%$ of patients received combinations such as cyclophosphamide and epirubicin. The study protocol also allowed for dose escalation depending on the pharmacokinetic results as well as clinical toxicity and efficacy according to the judgment of the treating physician. Median time to treatment failure in our study was 9.0 (0.6-24.2)months, and this is comparable to the time to treatment failure of modern chemotherapy regimens such as the docetaxel plus bevacizumab combination (8 months) [14]. In the trial reported by Scottë et al. the cumulative dose of docetaxel was $810(150-1275) \mathrm{mg} / \mathrm{m}^{2}$, and FG reduced the CTCAE G2 nail toxicity from $20 \%$ to zero [6]. In a study of a Japanese patient population who received a $300-\mathrm{mg} / \mathrm{m}^{2}$ or higher dose of docetaxel, the incidence of CTCAE G2 nail toxicity was $14 \%$ (without protection in a historical control) versus $4.4 \%$ (FG protected) [15]. The cumulative and lowest total docetaxel dose in our study is similar to those in the two studies cited previously. Furthermore, our study suggests that the degree of docetaxel exposure might not be an important causative factor for DNT occurrence.

FG are usually dried overnight after use and then frozen overnight or longer, which requires each institution to keep at least $80 \mathrm{FG}$ for ten docetaxel-treated patients per day. The commercial cost of FG in Japan is $¥ 28,000$ per glove. It is also necessary to have a special freezer at -25 to $-30^{\circ} \mathrm{C}$ to prepare FG. Since the cost of FG is not covered by health care insurance in Japan, a limited number of institutions use FG for patients who receive docetaxel. On the other hand, the method used in this study requires only two $\mathrm{FG}$ for each patient and requires only 90 -min preparation, which means that 20 FG is enough to treat ten docetaxel-treated patients per day. It is also unnecessary to have a special freezer, since the freezer compartment of a household refrigerator is enough to maintain the temperature at -10 to $-20^{\circ} \mathrm{C}$. This method is therefore economically highly beneficial. In addition, the more convenient method used in this study is not only as effective as the standard method but causes less discomfort.

Acknowledgements This work was supported by a grant-in-aid for scientific research by Japan's Ministry of Education, Culture, Sports, Science and Technology [grant no. 19590533]. We are grateful to Ms. Chisaki Chikuda and Mio Iiboshi, RNs, for their help with an evaluation of nail toxicities and Ms. Naoko Yonesaku and Mariko Inoue for administrative help.

\section{Disclosures None.}

Open Access This article is distributed under the terms of the Creative Commons Attribution Noncommercial License which permits any noncommercial use, distribution, and reproduction in any medium, provided the original author(s) and source are credited.

\section{References}

1. National Comprehensive Cancer Network (2011). NCCN clinical practice guidelines in oncology: myeloid growth factors, V.1. 2011. http://www.nccn.org/professionals/physician_gls/pdf/myeloid_growth.pdf. Accessed 9 May 2011

2. Smith TJ, Khatcheressian J, Lyman GH, Ozer H, Armitage JO, Balducci L, Bennett CL, Cantor SB, Crawford J, Cross SJ, Demetri G, Desch CE, Pizzo PA, Schiffer CA, Schwartzberg L, Somerfield MR, Somlo G, Wade JC, Wade JL, Winn RJ, Wozniak AJ, Wolff AC (2006) 2006 update of recommendations for the use of white blood cell growth factors: an evidence-based clinical practice guideline. J Clin Oncol 24(19):3187-3205. doi:10.1200/ JCO.2006.06.4451

3. National Comprehensive Cancer Network (2011). NCCN clinical practice guidelines in oncology: antiemesis, V.3.2011. http://www. nccn.org/professionals/physician_gls/pdf/antiemesis.pdf. Accessed 9 May 2011

4. Kris MG, Hesketh PJ, Somerfield MR, Feyer P, Clark-Snow R, Koeller JM, Morrow GR, Chinnery LW, Chesney MJ, Gralla RJ, Grunberg SM (2006) American Society of Clinical Oncology guideline for antiemetics in oncology: update 2006. J Clin Oncol 24(18):2932-2947. doi:10.1200/JCO.2006.06.9591

5. Minisini AM, Tosti A, Sobrero AF, Mansutti M, Piraccini BM, Sacco C, Puglisi F (2003) Taxane-induced nail changes: incidence, clinical presentation and outcome. Ann Oncol 14(2):333-337

6. Scottë F, Tourani JM, Banu E, Peyromaure M, Levy E, Marsan S, Magherini E, Fabre-Guillevin E, Andrieu JM, Oudard S (2005) Multicenter study of a frozen glove to prevent docetaxel-induced onycholysis and cutaneous toxicity of the hand. J Clin Oncol 23 (19):4424-4429. doi:10.1200/JCO.2005.15.651

7. Katsimbri P, Bamias A, Pavlidis N (2000) Prevention of chemotherapy-induced alopecia using an effective scalp cooling system. Eur J Cancer 36(6):766-771 
8. Lemenager M, Lecomte S, Bonneterre ME, Bessa E, Dauba J, Bonneterre J (1997) Effectiveness of cold cap in the prevention of docetaxel-induced alopecia. Eur J Cancer 33 (2):297-300

9. Ridderheim M, Bjurberg M, Gustavsson A (2003) Scalp hypothermia to prevent chemotherapy-induced alopecia is effective and safe: a pilot study of a new digitized scalp-cooling system used in 74 patients. Support Care Cancer 11(6):371-377. doi:10.1007/ s00520-003-0451-y

10. Mahood DJ, Dose AM, Loprinzi CL, Veeder MH, Athmann LM, Therneau TM, Sorensen JM, Gainey DK, Mailliard JA, Gusa NL et al (1991) Inhibition of fluorouracil-induced stomatitis by oral cryotherapy. J Clin Oncol 9(3):449-452

11. Takashima S, Nakata K, Kameno K, Yonesaku N, Teramukai S, Yanagihara K, Ishiguro H (2006) Observational study of docetaxel-induced nail-related adverse event and modification of hand cooling method using frozen glove. J Jpn Soc Cancer Ther (41):907

12. Taxotere (docetaxel) [package insert]. Paris, France: Sanofi Aventis.
13. Harvey V, Mouridsen H, Semiglazov V, Jakobsen E, Voznyi E, Robinson BA, Groult V, Murawsky M, Cold S (2006) Phase III trial comparing three doses of docetaxel for second-line treatment of advanced breast cancer. J Clin Oncol 24(31):4963-4970. doi:10.1200/JCO.2005.05.0294

14. Miles DW, Chan A, Dirix LY, Cortes J, Pivot X, Tomczak P, Delozier T, Sohn JH, Provencher L, Puglisi F, Harbeck N, Steger GG, Schneeweiss A, Wardley AM, Chlistalla A, Romieu G (2010) Phase III study of bevacizumab plus docetaxel compared with placebo plus docetaxel for the first-line treatment of human epidermal growth factor receptor 2-negative metastatic breast cancer. J Clin Oncol 28(20):3239-3247. doi:10.1200/ JCO.2008.21.6457

15. Sakurai M, Todaka K, Takada N, Kamigaki S, Anami S, Shikata A, Ueno H, Iseki C, Fujii C, Fujino M, Yamamura J, Masuda H, Ishitobi M, Nakayama T, Masuda N (2008) Multicenter phase II study of a frozen glove to prevent docetaxel-induced onycholysis and cutaneous toxicity for the breast cancer patients (Kinki Multidisciplinary Breast Oncology Group: KMBOG-0605). San Antonio Breast Cancer Symposium, San Antonio 